\title{
The Women's Empowerment in Livestock Index
}

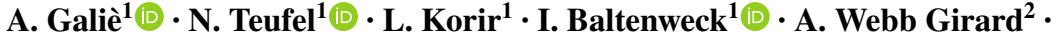 \\ P. Dominguez-Salas ${ }^{1,3} \cdot$ K. M. Yount ${ }^{4,5}$
}

Accepted: 22 May 2018 / Published online: 31 May 2018

(C) The Author(s) 2018

\begin{abstract}
The empowerment of women in the livestock sector is fundamental to achieve gender equality. It also is instrumental for increased household productivity and improved household health and nutrition. Diverse strategies exist to empower women, yet these strategies are difficult to prioritize without a reliable and adapted means to measure women's empowerment. One quantitative measure is the Women's Empowerment in Agriculture Index (WEAI). Despite its reliability in certain agricultural contexts, the WEAI requires adaptation in settings where livestock farming is the dominant form of livelihood. Using the WEAI as a starting point, a multidisciplinary team of researchers developed the Women's Empowerment in Livestock Index (WELI), a new index to assess the empowerment of women in the livestock sector. This paper presents the WELI and the dimensions of empowerment it includes: (1) decisions about agricultural production; (2) decisions related to nutrition; (3) access to and control over resources; (4) control and use of income; (5) access to and control of opportunities; and (6) workload and control over own time. The paper illustrates the use of the WELI by introducing pilot findings from dairy smallholders in four districts of northern Tanzania. The paper addresses considerations for the appropriate use and adaptation of the WELI to balance the needs for context specificity and crosscultural comparisons; it also discusses its limitations. The paper recommends participatory and qualitative methods that are complementary to the WELI to provide context-specific insights on the processes of women's empowerment in the livestock sector.
\end{abstract}

\section{A. Galiè}

a.galie@cgiar.org

1 International Livestock Research Institute (ILRI), P O Box 30709, Nairobi 00100, Kenya

2 Nutrition and Health Sciences, Laney Graduate School, Emory University, Atlanta, USA

3 The London School of Hygiene and Tropical Medicine, London, UK

4 Hubert Department of Global Health, Emory University, Atlanta, USA

5 Department of Sociology, Emory University, Atlanta, USA 
Keywords Economic empowerment $\cdot$ Index $\cdot$ Livestock $\cdot$ Tanzania $\cdot$ Weai $\cdot$ Mixed methods $\cdot$ Gender

\section{Introduction}

This article introduces the Women's Empowerment in Livestock Index (WELI), a standardized measure to capture the empowerment of women involved in the livestock sector. Empowerment of the most marginal farmers, and rural women in particular, is an identified means to improve gender equality and to reduce or eliminate hunger and poverty (UN Women et al. 2012) by increasing farm productivity through technological and institutional improvement (FAO 2011; Galiè 2013a). The 2015 United Nations Sustainable Development Goal 5 prioritizes gender equality and the empowerment of women and girls because both are fundamental human rights, and instrumentally, are foundational for a sustainable future. Goal 5 includes a target on "Enhanc[ing] the use of enabling technology, specifically information and communications technology, to promote the empowerment of women" (Goal 5: Achieve gender equality and empower all women and girls, n.d., Goal 5 Targets). As technological innovations in agriculture continue, Goal 5 is meant to ensure that women and girls are included in ways that are empowering to them, and therefore, that women are central to the success of agricultural research for development (AR4D) programs, such as those undertaken by CGIAR (Our Strategy, n.d.). One such CGIAR research program, Livestock and Fish (L\&F), formed the background of this study.

Numerous strategies have been proposed and used to enhance the empowerment of farmers in low- and middle-income countries. Some strategies have focused on empowerment through education and marketing training (Emory University and UN World Food Programme n.d.); whereas, others have focused on financial empowerment through microenterprise interventions; and still others on political empowerment through leadership training and quotas (Goldman and Little 2015; Halim et al. 2015, 2016). Similarly, within AR4D, empowerment has been associated with various approaches to development, for instance focusing on access to and control over resources (Ogato et al. 2009) or food security (Negin et al. 2009). Yet, unless empowerment can be conceptualized clearly, its processes articulated, and its outcomes measured, interventions to enhance women's empowerment likely will fall short of expectations (Saith 2006). Therefore, efforts to refine both definitions and measures of women's empowerment within sectors of development continue to be needed (Richardson 2017; Yount 2017).

The usefulness of communicating single-item and composite indices to show program impact and to build political commitment is undeniable (Ferreira and Lugo 2013). The Women's Empowerment in Agriculture Index (WEAI) was created in 2012 as part of the USAID's Feed the Future initiative to measure individual empowerment in agriculture while allowing for worldwide comparison. The index was developed to overcome the limitations of existing tools to measure quantitatively the empowerment of women farmers (Alkire et al. 2013), enabling programs to assess their progress on enhancing selected dimensions of women's empowerment, and therefore, increasing their attention to the issue. However, this and other approaches to measure empowerment in agriculture focus on crop farming, with less attention to livestock farming. Livestock farming contributes $33 \%$ of GDP worldwide (The World Bank 2009) - a percentage that reaches $60 \%$ in the main L\&F project sites in Tanzania involved in the MoreMilkiT project (see below). Yet, only $30 \%$ of questions in the WEAI focus on livestock. Moreover, characterizing women's 
empowerment in livestock through specific activities-rather than through livestock keeping overall—seems more appropriate to obtain quality information (see below).

Notably, livestock farming provides specific gendered challenges and opportunities, with implications for the empowerment of all farmers, their household food security, and the security of their livelihoods. Livestock are a strategic entry point to enhance the nutrition of the poor, particularly during the first 1000 days of life, given that livestock provide nutrient-rich foods, such as milk or meat, which are shown to improve growth and cognitive functioning, respectively (Grace et al. 2014; Neumann et al. 2007). Women have a central role in most countries as food producers and providers (Jiggins 2011) and control (some) livestock products that are essential for food and nutrition security (Njuki and Sanginga 2013). Also, women represent the majority of poor livestock keepers (FAO 2011).

On these bases, supporting the empowerment of women involved in the livestock sector is an important end in itself, and a promising instrumental pathway to reduce household poverty and to enhance household nutrition. Livestock also offers a unique opportunity for the empowerment of rural women, who are more likely to access and control livestock and their products than other productive resources such as land and machinery (Galiè et al. 2015; Njuki and Sanginga 2013). Thereby, livestock also is an important means of enhancing gender equity in livestock systems and contributing to gender equality. Gender equity is defined here as equivalence of life outcomes for women and men achieved through strategies that address the different needs, interests, access to resources and power of women and men. This concept differs from gender equality, which assumes a level playing field for women and men in a society where gender biases are removed (Reeves and Baden 2000). Yet, rural women, more than men, face constraints specific to the livestock sector including, for example, limited access to animal health information and services, inadequate land for forage production, and poor access to improved breeds (Galiè et al. 2017a; Njuki and Sanginga 2013).

Therefore, developing a measure to capture the empowerment of women involved in the livestock sector is important to explore how livestock and women's empowerment interconnect, and particularly, how women's empowerment can be supported through livestock. While the WEAI captured empowerment in agriculture in general (including also aspects of livestock together with crops and fish), teams from the International Livestock Research Institute (ILRI) and Emory University identified a mismatch between the limited attention to livestock issues in this tool and the importance of this sector for rural communities in East Africa. They, therefore, developed the WELI in 2015 to assess, quantitatively, the empowerment of women in agriculture with a specific focus on livestock production in selected sites in rural Tanzania.

In Tanzania, an estimated $16 \%$ of households are poor, and $8 \%$ are food insecure (World Food Program 2012). Roughly 62\% of households depend on livestock for their livelihoods, and livestock contributes an average of $14 \%$ of total rural annual income (Ministry of Agriculture Livestock and Fisheries 2016). Livestock farming is mostly for self-consumption, and productivity is low. Livestock keeping seems to be associated with poverty, and particularly female poverty (Ministry of Agriculture Livestock and Fisheries 2016). Women manage herds that are, on average, two thirds the size of those managed by men, they control less valuable species (mostly poultry while men control cattle), are more commercially oriented but earn less than men, and are less likely to use key inputs, such as labor, fodder, and vaccinations (Covarrubias et al. 2012).

In this article, we introduce the WELI and describe how it can be used for data collection and analysis to assess the empowerment of women in the livestock sector in East Africa, particularly in households where livestock is the main agricultural activity. The 
WELI focuses on key areas of livestock production, such as animal health, breeding and feeding; and use of livestock products, such as animal-source-food processing and marketing. We address considerations about use of the WELI for cross-cultural comparisons, adaptation of the WELI for contextual relevance, and qualitative research as a useful complement to monitor processes of empowerment. We present pilot findings from Tanzania that elucidate methodological aspects of the WELI, and we underscore the value of psychometric validation of the WELI, and all future derivatives of the WEAI tools. The full analysis of the data is presented elsewhere.

\section{Conceptual Framework}

A common definition of empowerment derives from the work of Sen (1990) and Kabeer (1999), who see empowerment as a process of enhancing individuals' capacity for selfdetermination, that is, their capability of living the lives that they have a reason to value. Other definitions focus on empowerment as an individual process of self-awareness and development (Eyben and Napier-Moore 2009); as a relational change in power dynamics (Drydyk 2013); as changes in power structures (Kilby 2006). Santarius and Sachs (2007) operationalize self-determination through three key components: recognition (by both the individual herself and society) of the roles individuals choose to take in society, access to resources that are needed to sustain a livelihood, and access to opportunities that are necessary to actualize self-determination. "Decision-making" and "autonomy" are two corollaries of self-determination. Decision-making refers to the ability to take one's own decisions that affect one's own life; it is a necessary means for self-actualization and selfdetermination that are two basic principles of empowerment (Cornwall 2007). "Autonomy" is generally understood as "freedom from external control or influence" and, in women's empowerment studies, is framed as freedom for women from patriarchal oppression, to realize their power, and to have their rights as individuals recognized (Kabeer 2011).

Kabeer (2012) argues for locally grounded concepts of empowerment, given that individualistic and rights-based approaches common in international discourses have limited resonance with the daily lives of men and women from countries with a weak culture of individual rights. Although debate on empowerment has strong roots in Africa (see Nobel laureate Wangari Maathai's work with the Green Belt Movement [Who We Are 2017]), the concept and its meaning beyond "improving women's lives" has evolved little on the continent (Tsikata and Darkwah 2014). In their study on empowerment in Ghana, Tsikata and Darkwah (2014), addressed this conceptual gap based on the belief that empowerment is specific in time and place, and therefore, needs to be contextualized. The definitions of empowerment reported in their study focused on the more common individualistic approaches about the ability of expanding one's choices, but also more collective conceptualizations about the ability to empower "others". A third conceptualization they mentioned included "consciousness" or awareness of the state of being that emerges in certain empowering or disempowering situations (Tsikata and Darkwah 2014).

Friis-Hansen and Duveskog (2012) found two dimensions of empowerment to be relevant in East Africa: self-perceptions of farmers about their power and agency in life, such as the power to influence their lives and community, and actual physical expressions of agency in their daily lives, such as access to and control over productive assets, knowledge, and services. Heckert and Fabic (2013) tested the usefulness in four countries in sub-Saharan Africa (SSA) of empowerment indicators used by the United States Agency 
for International Development (USAID) in the Demographic and Health Surveys (DHS). These surveys are used to collect health and population data worldwide-including empowerment data-and use empowerment indicators developed in Southeast Asia. They report that new empowerment indicators-related to the DHS dimensions of economic empowerment, legal rights, decision-making, and social norms and attitudes-emerged as central for empowerment and health (Miedema et al. n.d.). These studies show that context may affect meanings of empowerment and that the relevance of specific empowerment dimensions and indicators may vary with the field of inquiry-such as health for Heckert and Fabic's study or crops and livestock, in the case of our study.

On the one hand, the feasibility of developing a universal yardstick of empowerment that permits comparisons across individuals, groups, and countries is debated (Galiè 2013a; Tsikata and Darkwah 2014). Composite indices that aggregate diverse dimensions (Booysen 2002; Ravallion 2012), such as those related to human development (Herrero et al. 2012; McGillivray 1991; Sagar and Najam 1998) and poverty (Alkire and Foster 2011; Alkire and Santos 2010), raise issues, such as the choice of dimensions on which to focus, the suitable methods to weigh component indicators and dimensions (Ferreira and Lugo 2013; Ravallion 2011; Yount et al. 2015), and more broadly, the most relevant scope of such measures (Richardson 2017). Tools developed for comparison of empowerment across countries through macro level indicators, such as the Gender Development Index (GDI) or the Gender Empowerment Measure (GEM) have been criticized for providing aggregate data only, and no information on, for example, age or social belonging at individual levels, which are recommended for a gender analysis of empowerment (Alkire et al. 2013; Ibrahim and Alkire 2007; Miedema et al. 2017).

On the other hand, tools developed for community or individual scales, which may better address the complexity of individual empowerment processes, have been criticized for their limited generalizability, with wider implications for informing policy, and consequently, the political commitment toward enhancing empowerment and gender equity in favor of more quantifiable economic goals (Alkire et al. 2013). How far should indicators be universal to enable global comparisons, or contextualized to ensure local relevance (Friis-Hansen and Duveskog 2012; Tsikata and Darkwah 2014)? Can a balance be struck between these agendas?

In light of this debate, this article presents the process by which the WELI was conceptualized, developed, and tested for use in observational and impact evaluation research in the livestock sector. The article presents preliminary findings, overall and across demographic subgroups, with recommendations for interpretation that acknowledge influential assumptions in the estimation of the WELI and probably measures like it. Finally, considerations in applying versus adapting the WELI to other contexts as well as combining it with qualitative and participatory approaches are discussed, so that the WELI may be used appropriately in other contexts to elucidate complex individual and collective empowerment processes while producing comparable findings across sites.

\section{Materials and Methods}

\subsection{Formative Process to Develop the Initial WELI}

In 2015, interdisciplinary teams from ILRI and Emory University developed a women's empowerment index specific to the Tanzania livestock sector. Three major sources 
informed the development of the WELI. First, general components of empowerment, such as "contribution to decisions" and "autonomy in decisions" provided a conceptual basis for the tool. Second, existing dimensions and indicators of the WEAI (specifically the domains "production", "resources", "income", and "time" (time was used differently in the WELI, see below) informed the sectoral dimensions and component indicators to be included. Third, evidence from an ongoing project (MoreMilkiT, see below), a formative study undertaken by Emory University in 2014, and consultations with ILRI livestock experts were used to identify dimensions considered key in the empowerment of women dairy farmers pertaining to livestock farming, dairy value chain development and nutrition based on animal source foods in Tanzania.

Box 1. Findings from the formative research in Tanzania

The qualitative formative study undertaken by Emory University used focus group discussions with women and men in intensive and extensive livestock communities including both cattle keepers and non-cattle keepers. In-depth interviews were also conducted with community health workers, agricultural extension officers, village leaders, district leaders, and gender specialists in Tanga and Morogoro, Tanzania. In brief, cattle were perceived as a secure way of storing one's wealth and acted as a type of currency for dowries. Cattle were a status symbol, a labor source to transport goods and plow land, as well as a source of meat, milk, and fertilizer for agricultural produce. Both division of labor and decision-making were strongly gendered with implications for women's time use, foods available for household nutrition and capacity of women to engage in optimal child care practices. In general, men tended to care for the large livestock (buy/sell, graze, dip/spray, treat) while women worked with agriculture, small livestock, and the dairying aspects of cattle with varying levels of participation in large livestock activities. Men were considered the owners and sellers of cattle; only in rare circumstances could women own or sell cattle. While men were seen to have final authority in making decisions about livestock, women's contributions to decision-making were valued, though the extent to which women contributed to decision-making or the degree of value placed on their inputs varied considerably across communities and tribes. In some communities, for example, women had less authority regarding cattle management, but were fully in control of dairying activities, including authority over how to spend funds earned from dairying; in other communities, however, men had complete control over dairying and income generated from dairy.

Based on these findings from the formative research, in a systematic review comparison between the WEAI dimensions and with the support of a member of the WEAI team, the following dimensions were selected for the WELI: (a) decisions on agricultural production; (b) decisions related to nutrition; (c) access to and control over resources; (d) control over and use of income; (e) access to and control of opportunities; and (f) workload and control over own time. These dimensions were explored across the following livestock farming and nutrition dimensions: animal feeding; animal health; milking; preparation of animal products; animal breeding; marketing; crop farming for home consumption; crop farming for sales; obtaining agricultural input; non-farm income-generating activities; and wage and salary employment.

As with the WEAI, each dimension was operationalized with two to three indicators, measured through several contributing questions (Table 1). The definitions of these questions and how they were associated with each indicator were developed through intense field testing and exchanges with key informants during the formative research in the target area. Similar to the WEAI, a high degree of consistency amongst indicators and questions was maintained to ease data collection and analysis. While the tool focuses on livestock, other activities, such as crop farming or marketing, were included during the creation of indicators because they are considered essential for a complete picture of livestock rearing in small-scale farming households.

However, because the formative work showed that gender dynamics and roles vary between specific activities (such as ploughing and weeding or milking and breeding) and 


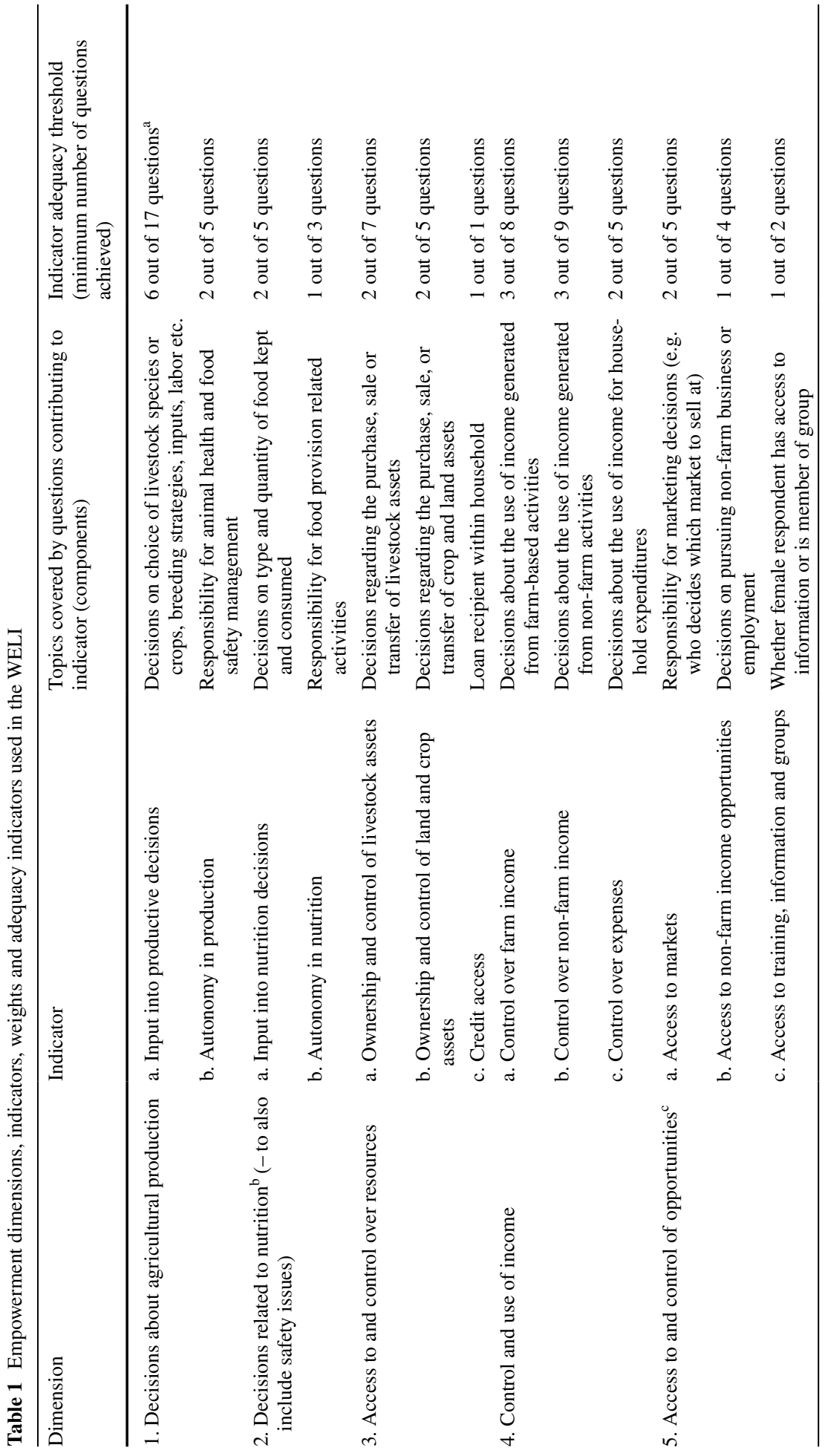




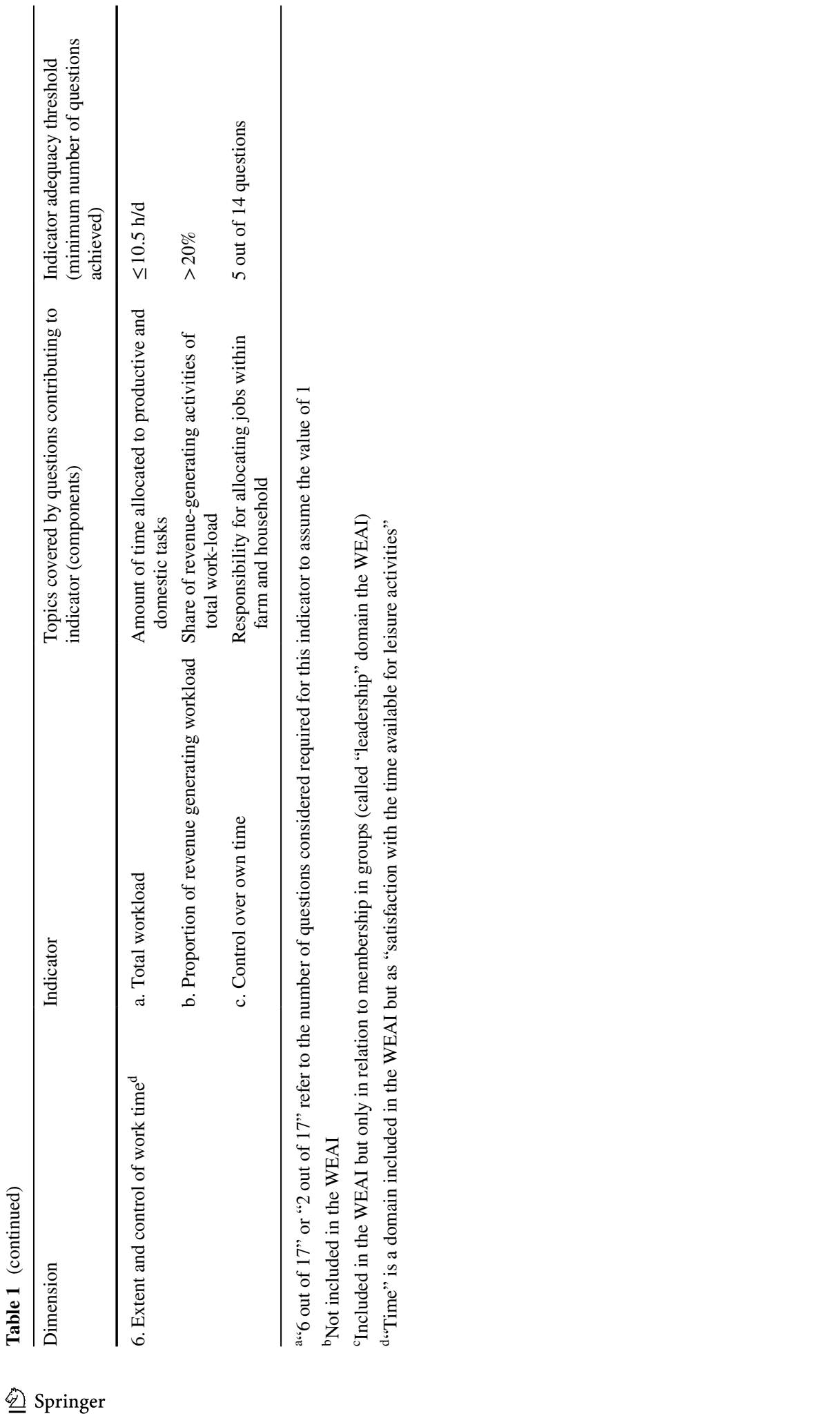


between livestock species, respondents struggled to characterize their contribution to higher-level activities, such as livestock keeping overall. Therefore, the authors decided to obtain in-depth and quality information on women's empowerment by measuring their contribution to very specific activities. This approach entailed focusing data collection on the two livestock species most relevant for women's empowerment: these were the species that the respondent considered to be most important for household well-being as well as the woman's well-being. This focus was not meant to create species-specific indices. Rather, it aimed at improving data quality and the relevance of results by directing questions towards what respondents themselves perceived to be the important issues and activities. Also, the detailed findings obtained for empowerment related to each livestock activity were considered important opportunities for development projects in targeting empowerment interventions more effectively. The pilot findings here refer only to the species that the respondents considered most important for the household (in the large majority of cases these were dairy cows).

\subsection{Geographic and Programmatic Setting of the WELI Pilot Test}

The WELI was piloted in four districts of the "More Milk in Tanzania" (MoreMilkiT) project (http://moremilkit.wikispaces.com/), led by ILRI. MoreMilkiT started in 2011 as a collaboration of academic and research institutions with support from Irish Aid. MoreMilkiT is working to reduce poverty and vulnerability, and to enhance food security among people with dairy-dependent livelihoods in 30 rural communities in Handeni, Lushoto, Kilosa and Mvomero districts of northeastern Tanzania (Fig. 1). The project works with smallholders, either settled, intensive cattle keepers, pastoralists, or extensive herders, linking them to rural and urban markets. MoreMilkiT adopted a gender approach from its inception to ensure gender inclusive dairy development and to avoid the transition of dairy households toward a market-based production system that would marginalize women and deprive them of their customary roles as milk handlers and food providers. The gender approach of the project focuses on enhancing the capacity in gender analysis of its partners; undertakes research to ensure that gender considerations are integrated in all project activities; and engages with gender transformative approaches (GTAs) to create an enabling environment supportive of more equitable gender norms.

\subsection{Participant Selection and Data Collection for the WELI Pilot}

Between June and August 2015, eight enumerators from Sokoine University of Agriculture were trained for 1 week on the WELI and nutrition surveys. The survey was conducted among 373 women living in the 461 households that were monitored regularly for the MoreMilkiT project. The gap between the number of women surveyed and the households monitored under MoreMilk related to the fact that only women age 15 years or older were eligible in our study. Also, $4 \%$ of eligible households had temporarily moved away in search of pasture for their livestock, and could not be surveyed. In all the districts livestock farming is the main economic activity. Kilosa and Handeni districts represent mostly extensive, agro-pastoral livestock keeping with precommercial milk production for rural consumption. Mvomero and Lushoto districts have significant semi-intensive and intensive livestock production with relatively more commercial milk production for urban consumption. 


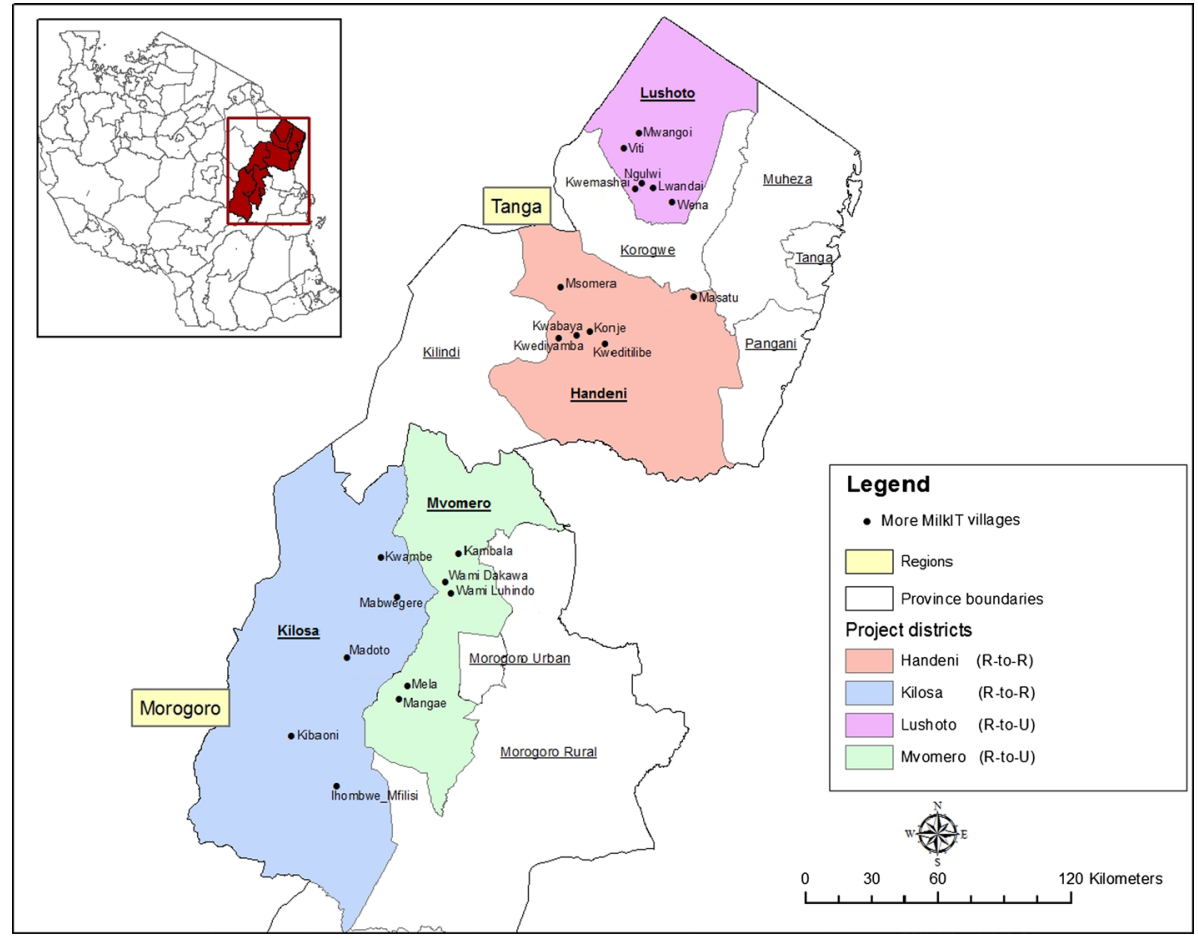

Fig. 1 The four districts where the Women's Empowerment in Livestock Index (WELI) was developed and applied. Source: MoreMilkiT project

\subsection{Developing and Piloting the WELI}

Here, we present our work developing and piloting the WELI. We first describe each dimension of empowerment covered in the WELI and justify its inclusion with reference to the literature. Each dimension is operationalized into two or three indicators. Each indicator is in turn measured through survey questions. We grouped the questions into indicator components to facilitate an overview of the issues explored (Table 1). We then show the steps taken to calculate the WELI and highlight definitions of indicators and questions that are assumed to affect the final output. We finally present initial results from the Tanzanian survey, comparing alternative indicator calculation procedures.

\subsubsection{Dimensions of Empowerment in the WELI}

Decisions about agricultural production This dimension includes two indicators: (a) input into productive decisions (measured through questions grouped under the component "decisions on choice of livestock species or crops, breeding strategies, inputs, labor etc.") and (b) autonomy in production (measured through "responsibility for animal health and food safety management") (Table 1). 
Decision-making about the sourcing, production and use of crop and livestock productive resources is a key element of empowerment in farm households. In the case of decision-making about crops, for example, extensive research has shown that women and men often have different crop trait preferences and needs, and different constraints and opportunities to access seed and varieties (Chiwona-Karltun et al. 1998; Farnworth and Jiggins 2003; Galiè 2013b). These differences affect the ability of women and men to access and adopt technologies that can improve their agricultural production and control over it. Similarly, women and men often have different preferences for livestock species, breeds and products. In a study in Tanzania, for example, women were found to prefer (or give more importance to) chickens, chicken meat and manure, while men preferred cattle, cow milk, and eggs (Njuki and Sanginga 2013; Waithanji et al. 2013). The choice of species and breeds of livestock to keep in the household, or whether to engage in livestock raising at all, affect the labor inputs, control over livestock and related products and revenues, and access to and control over opportunities (such as marketing) of individuals in the household (FAO 2012; Kristjanson et al. 2014).

Decisions about nutrition This dimension includes two indicators: (a) input into nutrition decisions (measured through "decisions on type and quantity of food kept and consumed") and (b) autonomy in nutrition (measured through "responsibility for food provision related activities") (Table 1). Nutrition was not a dimension included in the WEAI (it was included in pro-WEAI, however, a revision of the WEAI).

Evidence connects women's empowerment to household nutrition (Cunningham et al. 2015; Malapit and Quisumbing 2015). Gender relations, women's bargaining power and patterns of work, and women's own nutritional status have been the main determinants of children's nutritional status (Agrawal 2011 and Young 2012 cited in Mwaseba and Kaarhus 2015). Cunningham et al. (Cunningham et al. 2015) show that maternal decision-making, and control and autonomy in the household are likely to improve child nutrition in agricultural households of Nepal. Malapit and Quisumbing (2015) show that different dimensions of empowerment affect the nutritional status of household members differently. In a study in Tanzania, Mason et al. (2014) discuss the apparent contradiction between evidence that women favor food expenditures if compared to men (Duflo 2003; World Bank et al. 2009) and evidence that female-headed households are generally more food insecure. They argue that women household headship is linked to issues of household impoverishment and empowerment that are key determinants of access to food. The authors show that livestock availability for women increases food production and availability in their households.

However, no studies have confirmed, yet, that control over household nutrition is a key contributor to women's empowerment. But, because of the strong correlation between empowerment and nutrition, this dimension is included in the WELI (Sinharoy et al. 2018). The findings from the WELI can contribute to exploring this correlation in general and in the framework of livestock. The WELI also captures decision-making about intra-household food allocation which may be a key challenge to dietary adequacy even in food-secure households.

Access to and control over productive resources This dimension includes the indicators: (a) ownership and control of livestock assets (measured through "decisions regarding the purchase, sale or transfer of livestock assets"); (b) ownership and control of land and crop assets (measured through "decisions regarding the purchase, sale, or transfer of crop and land assets"); and (c) credit access (measured through "loan recipient within household") (Table 1). 
A large body of literature shows how access to and control over productive resources are positive contributors to women's empowerment (FAO 2011; Kabeer 1999; Trommlerová et al. 2015). The World Bank (2009) found that the lower productivity of fields owned by women and girls relates to their limited access to productive resources (especially land), technologies and information. Assets help manage vulnerability, provide collateral, help accumulate wealth, and increase social empowerment and political engagement (Quisumbing et al. 2015). For Bebbington (1999), assets are a means for empowerment because they are necessary to build livelihoods, to make living meaningful and to act and challenge the structures affecting a living (cited in Meinzen-Dick et al. 2014). At the same time, gender dynamics affect how different individuals value, own, accumulate, control, and use different assets (Quisumbing et al. 2015). Kilby (2006), emphasizes how empowerment is itself a means for the most marginalized individuals to improve their access to community resources, highlighting how disempowerment coincides with a lack of ownership and inability to accumulate, control, and use resources.

Livestock are important assets for women, who can access and control them more easily than they can access and control land or other physical or financial assets (Kristjanson et al. 2010; Rubin et al. 2010). Access to and control of livestock has contributed to women's empowerment, especially in livestock-dependent communities like those involved in the MoreMilkiT project (Flintan 2008; Trommlerová et al. 2015). In her study across Indonesia, Bolivia, Peru and Kenya, Valdivia (2001), shows that women's control over livestock, livestock products and the productive resources needed to raise livestock, increases women's bargaining power, access to animal source foods that they use mostly to benefit their children and ultimately their empowerment. A study in Tanzania, Ethiopia, and Nicaragua showed how the informal nature of livestock ownership affected perceptions of "what it means to own livestock," with women and men respondents using various criteria such as "who contributes most labor in the management of the livestock", "who sourced it" or "who controls the revenues" (Galiè et al. 2015). The WELI thus, does not include questions on "livestock ownership" but focuses on access to and control over livestock or its management.

Control over and use of income This dimension includes the indicators: (a) control over farm income (measured through "decisions about the use of income generated from farmbased activities"); (b) control over non-farm income (measured through "decisions about the use of income generated from non-farm activities"); and (c) control over expenses (measured through "decisions about the use of income for household expenditures") (Table 1).

The association between control over income and women's empowerment, which is often referred to as economic empowerment, has been established and the focus of much development work in the last decades (Hill 2011; Mayoux and Hartl 2009). Mwaseba and Kaarhus (2015) assessed empirically women's limited involvement in the market sphere and in controlling income in Tanzania. They warn that the introduction of marketable assets - in the case of MoreMilkiT project, increased milk production to be sold in the market—can lead to increased involvement of men in controlling assets previously controlled by women. This shift in control may result in the marginalization of women and their increased dependence on men, leading to disempowerment. They also found that increases in milk production in two ethnic groups of Tanzania, did not result in improved nutrition of children because women, who were in charge of providing food for the children, lacked decision-making power over the use of milk income, which was used for non-food expenses under men's responsibility. Such evidence shows 
how control over income entails control over household spending priorities and it also strengthens the link between empowerment and household nutrition.

Access to and control of opportunities This dimension includes three indicators that capture: (a) access to markets (measured through "responsibility for marketing decisions" (e.g. who decides at which market to sell); (b) access to non-farm income opportunities (measured through "decisions on pursuing non-farm business or employment"); and (c) access to training, information and groups (measured through "whether female respondent has access to information or is member of group") (Table 1).

Access to and control of opportunities has only the indicator "membership in groups" in common with two indicators of the WEAI "leadership" domain (the second was "comfort to speak in public" which according to formative research, was not considered important to respondents). The three selected indicators for this domain were considered important in the WELI based on a review of the literature and findings from the formative study. Schmid (1987) defines "opportunities" as "the available lines of action open to an individual [...] so that he or she might act without seeking the formal consent of others" (Schmid 1987: 9). Providing individuals with "equal opportunities" translates into ensuring that they all have the potential to achieve the same outcomes by compensating for different environmental circumstances, such as gender inequities (Roemer 2008). Santarius and Sachs (2007) see access to and control of opportunities as necessary to make use of resources and to actualize self-determination, and therefore, empowerment. The formative study showed that gender norms in respondents' villages (e.g. about the threat that access to knowledge would make women independent from their husbands) prevented women from accessing information, market and employment opportunities.

Workload and control over own time This dimension includes the indicators: (a) total workload (measured through "amount of time allocated to productive and domestic tasks"); (b) proportion of revenue generating workload (measured through "share of revenue-generating activities of total workload"); and (c) control over own time (measured through "responsibility for allocating jobs within farm and household") (Table 1).

"Control over own time" was not included in the WEAI, which instead focused on satisfaction with the time available for leisure activities. This choice to include it in the WELI was determined by the following perspectives. The gendered division of labour usually results from decisions at individual, household and community levels and is influenced by gender norms (Agarwal 1997). Feminist scholars have shown how the gendered division of labour typically is unjust and to women's disadvantage (Robeyns 2003). The formative study in the Tanzania sites showed that-following customary labour arrangementswomen invested much of their time in livestock rearing but rarely in activities that brought revenues. Thus, control over time is important for empowerment because it allows women to allocate their efforts to their preferred activities, thereby contributing to their self-determination. Control by others of one's time is unlikely to lead to full control over achieving own goals. In their study in rural India, James et al. (2002), showed how women participants' increased control over own time enhanced their empowerment because women decided to get involved in revenue-generating activities that strengthened their intra-household decision-making and status.

\subsection{Calculating the Index}

Overview This overview presents how the above indicators were combined to compute the empowerment index. Notably, the method of scoring we present here is, for 
comparative purposes, analogous to standard methods for computing the WEAI and variants of the index. The WELI uses six dimensions of empowerment in livestock production as described above. It is based on data obtained from individual women from households that derive part of their livelihood from livestock production. Following the WEAI, each dimension received an equal weight of $1 / 6$, and, within each dimension, the respective indicators are also weighted equally. That is, for each dimension, the indicator weight is determined by the dimension's weight (1/6) divided by the number of the indicators in the particular dimension. For example, the agricultural production and nutrition dimensions consist of two indicators each (resulting in indicator weights of 1/12 for each indicator), while all other dimensions have three indicators each (resulting in an indicator weights of $1 / 18$ for each indicator). Each indicator is composed of several questions presented to the interviewed women (Table 1). There is no weighting at the question level; as the determination of the indicator values follows the procedure presented below.

Computation. To compute the WELI, an individual is evaluated at the question level and at the indicator level. At the question level, an individual's response is assessed to determine whether she has achieved a minimum level of empowerment for that specific question. For all questions on decisions, this minimum level is achieved if the individual made the decision herself or had at least some input in the decisions made. On total workload, the corresponding boundary definition of minimum level of achievement is "did not exceed $10.5 \mathrm{~h}$ per day"; while regarding the proportion of this total workload used for revenue generating work, a share of at least $20 \%$ is considered as achieving empowerment. All questions in which an individual is assessed as achieving the minimum level of achievement are coded as 1 , and 0 otherwise. At the indicator level, the associated question variables (coded 1 for achievement and 0 otherwise) are summed to generate the number of questions in which the individual has achieved minimum levels. An indicator is assumed to have been adequately achieved if a certain number of questions have met minimum achievement levels (Table 1, indicator "adequacy"). In this case, the value assigned is $1 ; 0$ otherwise. The definition of this certain number of questions within each indicator is an arbitrary decision within the WEAI methodology (Alkire et al. 2013). To introduce some consistency, achieving roughly one third of the included questions is assumed to be appropriate threshold value for indicator adequacy (see below). This assumption deviates from the WEAI, where for most indicators, only one question needs to be achieved for the indicator to be deemed adequate (regardless of the number of questions in the indicator). To illustrate the effects of this deviation, preliminary results are calculated following both procedures (and discussed in the Sect. 5 ). The indicator values then are weighted according to the weights described above and summed. This summation produces the WELI score, which ranges from 0 for the least empowered to 1 for the most empowered women in livestock. Computation of the WELI is inspired by the basic approach used by Alkire et al. (2013) and is computed as:

$$
W E L I_{i}=w_{1} I_{1 i}+w_{2} I_{2 i}+\cdots+w_{d} I_{d i}
$$

where $W E L I_{i}$ is the WELI score for individual $i, I_{d i}$ is coded 1 if person $i$ has adequacy in indicator $d$ or 0 otherwise, and $w_{d}$ is the weight assigned to indicator $d$. All 16 indicator weights sum to 1 .

However, depth of disempowerment (i.e. distance to a threshold of disempowerment) was not determined, as it appears questionable whether a commonly acceptable threshold of disempowerment, equivalent to the poverty threshold based on per capita income, can be defined. Also, within-household variation of empowerment was not calculated because the survey included only one respondent per household. 


\section{Pilot Results for Tanzania}

Analysis at the indicator level of the data collected in Tanzania revealed a wide variation in the proportion of women achieving adequacy in each of the indicators (Table 2). Based on the WELI definitions, few women achieved adequacy in credit, access to opportunities for non-farm income, and control over non-farm income. Moreover, only about $17 \%$ of the 373 women achieved adequacy in the proportion of revenue generating workload, meaning that the majority of them spent nearly all their time on non-revenue generating activities. A smaller proportion of women achieved adequacy in access to and control over livestock assets compared to access to and control over land and crop assets (this may be affected by the survey's focus on cattle (see discussion below)). Only in nutrition, access to information, training, groups, and control over own time did we find a majority of women achieving adequacy.

To assess the effects of alternative computational procedures on the magnitudes of estimated indicators, we compared the results of calculating empowerment index values according to WELI adequacy definitions with the results from processing with WEAIinspired definitions, both calculations being based on the same data from Tanzania. Unsurprisingly, we find considerably higher shares of respondents achieving adequacy with the WEAI-inspired calculation, especially for indicators comprised of many component questions. It is far more probable for an indicator to attain adequacy if only one question requires to be achieved, than if about a third of questions have to be achieved. The distribution of WELI score is roughly normal (Fig. 2), with most scores falling between 0.3 and 0.4 . Slightly more than $8 \%$ of the women had a WELI score of lower than 0.1 , while only few (2\%) scored over 0.8. The 0.8 boundary line shown in Figs. 2 and 3 is based on the WEAI definition of 'being empowered' (Alkire et al. 2013). This was included in the WEAI in order to establish baseline values of empowerment headcount ratios (i.e. $\%$ of empowered within the total population) that offer scope for monitoring change over time, similar to the poverty threshold allowing the measurement of poverty rates within populations. The boundary value was determined by sensitivity analysis using various cut-off values.

For comparison, the distribution of scores based on the WEAI-inspired definition of indicator adequacy also is presented in Fig. 3 (and discussed in the Sect. 5). The lower adequacy requirements of this approach lead to most respondents showing index values between 0.7 and 0.8 (21\%), just under the WEAI's empowerment threshold.

Table 3 shows overall WELI scores for the each of the four districts of Tanzania where the pilot was conducted. On average, WELI scores for women in Lushoto were the highest while they were lowest for women in Kilosa District. Women in Movomero District were second, closely followed by those from Handeni.

\subsection{Contribution of Dimensions and Indicators to Empowerment Scores}

To compare how dimensions and indicators contribute to WELI scores, the respondents were categorized into four quartiles by WELI score. For this they were first ranked by their WELI scores and then divided into four groups of equal size of 92 households. Thus, the first quartile contains the $25 \%$ of respondents with the lowest WELI scores. Figure 4 shows the WELI scores for these four groups and their composition. The indicators were grouped into dimensions, which also enabled assessment of the dimension contributions. The figure highlights that adequacy in the nutrition and the control over own time dimensions varies 


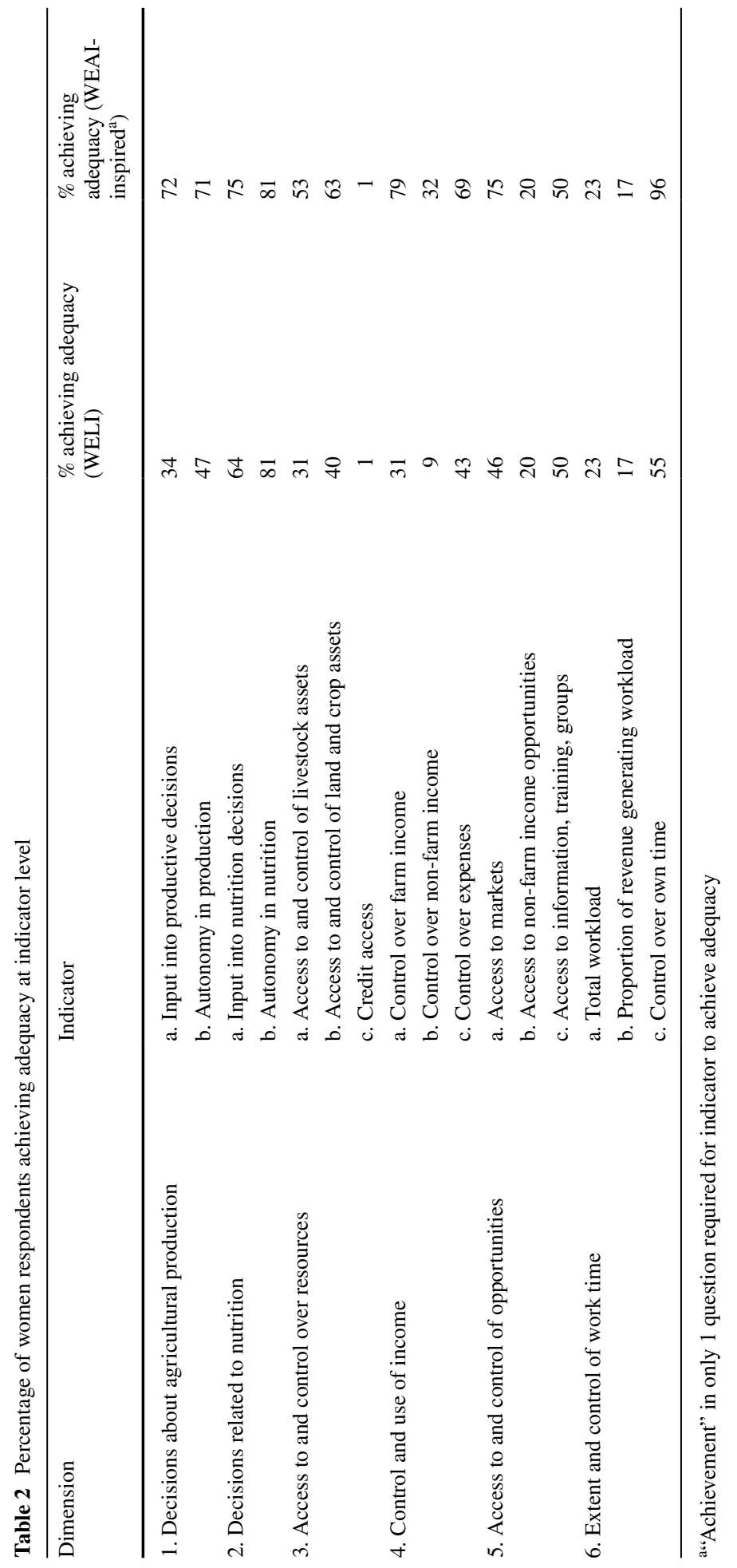




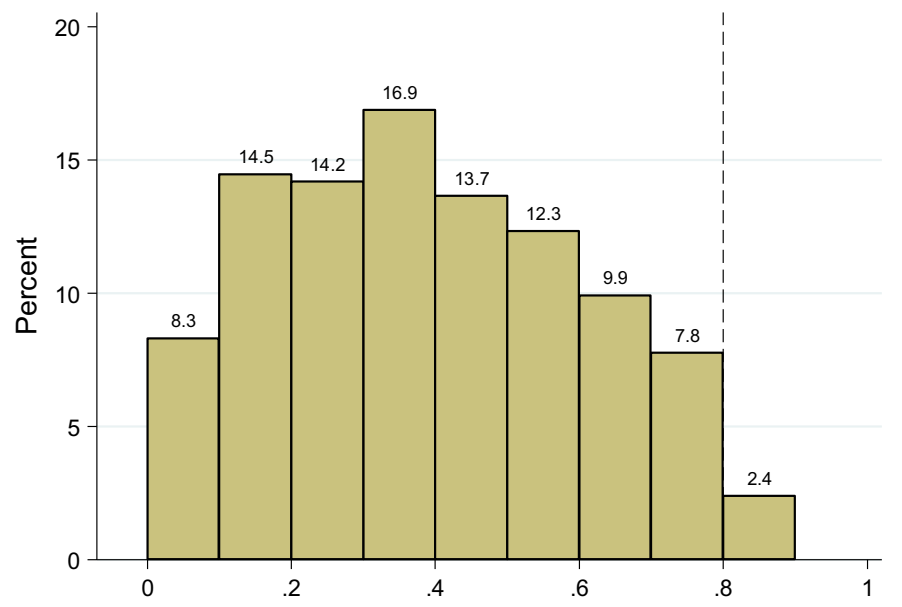

Women Empowerment in Livestock Index (WELI) score; $n=373$

Fig. 2 Percentage of survey respondents within WELI score bands (the 0.8 score boundary line illustrates WEAI definition of empowerment)

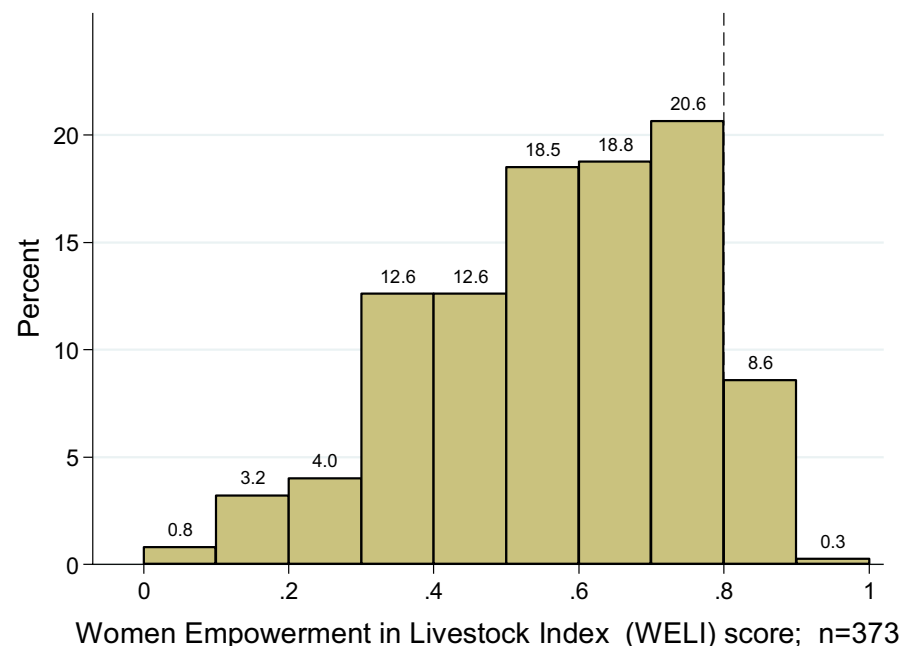

Fig. 3 Percentage of survey respondents within WELI score bands; index values calculated with WEAIinspired adequacy definitions (achievement in only 1 question required for indicator adequacy). The 0.8 score boundary line illustrates WEAI definition of empowerment

Table 3 WELI score aggregates, by district and total

\begin{tabular}{lrllllll}
\hline District & $\mathrm{n}$ & Mean & $\mathrm{SD}$ & Se (mean) & Median & Min & Max \\
\hline Mvomero & 79 & 0.37 & 0.20 & 0.02 & 0.33 & 0 & 0.83 \\
Kilosa & 75 & 0.30 & 0.17 & 0.02 & 0.28 & 0 & 0.72 \\
Handeni & 84 & 0.39 & 0.22 & 0.02 & 0.39 & 0 & 0.89 \\
Lushoto & 135 & 0.46 & 0.22 & 0.02 & 0.47 & 0 & 0.89 \\
Total & 373 & 0.39 & 0.22 & 0.01 & 0.39 & 0 & 0.89 \\
\hline
\end{tabular}


very little across the quartiles. On the other hand, adequacy in dimensions regarding the decisions on agricultural production, resources and income is almost non-existent in the first quartile but increases considerably with increasing WELI scores. In general, women across all quartiles have inadequacies in indicators of credit, non-farm income and access to non-farm opportunities for generating income. Also, women in the lowest quartiles show inadequacy in decisions on productive activities, control over livestock assets, farm income, expenses and access to markets. The levels of participation of women in non-farm activities and income-generating activities is generally low, and this explains the low levels of adequacy in these indicators. These relationships appear to highlight areas with substantial gaps in women's empowerment in livestock, leading to low WELI scores.

\subsection{Contribution of Dimensions to Empowerment Scores by District}

Figure 5 shows WELI score contributions by district. Similar to the comparison of WELI quartiles presented above, the nutrition dimension is almost the same across all the districts. In fact, this dimension appears to be the main contributor to the WELI in all districts. However, scores on the dimensions of "decisions on control and use of income" as well as "access to and control over opportunities" vary considerably. Their contributions to the WELI are lowest in Kilosa but highest in Lushoto, suggesting that these are the main dimensions leading to differences in the overall levels of women's empowerment in the livestock sector across the four districts.

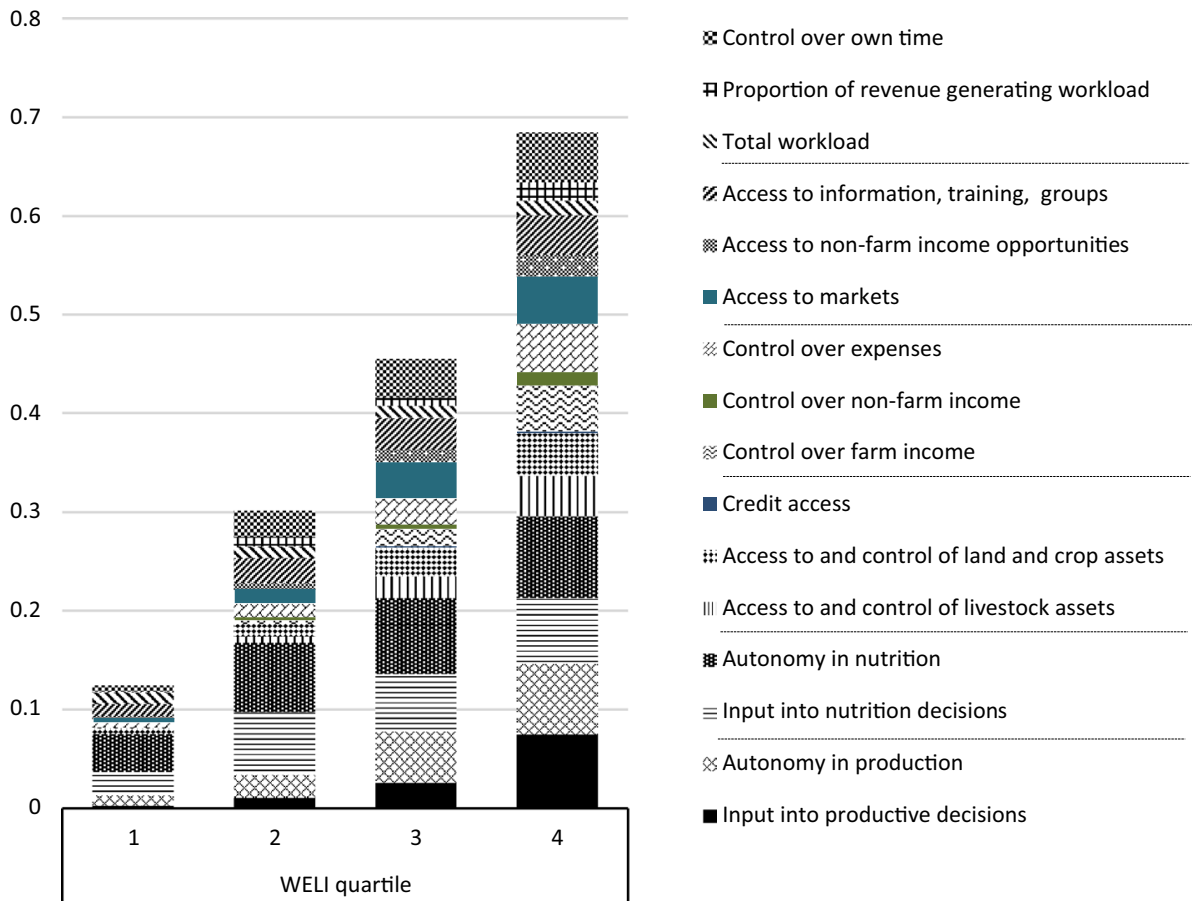

Fig. 4 Contribution of indicator values, grouped by dimension, to average WELI scores within WELI quartiles (373 households were ranked by their WELI scores and then divided into 4 groups of equal size) 


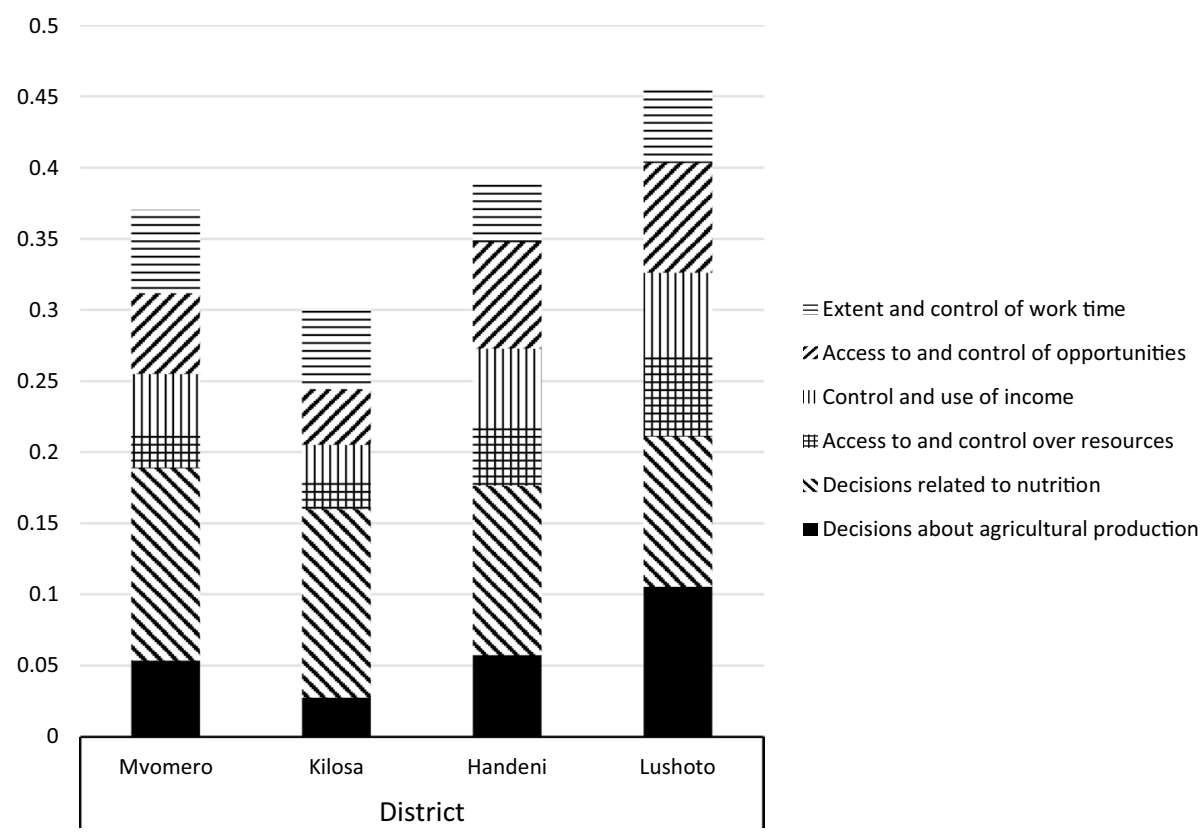

Fig. 5 Contribution of dimensions to WELI by district

\section{Summary of Findings and Discussion}

\subsection{The WELI as a Measure of Women's Empowerment in Livestock}

This study is the first to present the WELI, a measure to quantify the empowerment of women in the livestock sector using a quantitative scale that was developed through an intensive, interdisciplinary effort with attention to local context. Preliminary results from four districts in Tanzania show the value of the WELI in measuring women's empowerment in this sector. The tool provided rich data to compute scores for empowerment that can be used for comparison across individuals and over time. The WELI will therefore facilitate meaningful assessments of the effectiveness of project interventions to enhance the empowerment of women in this sector.

Overall, the average value for women's empowerment was 0.39 out of 1.00 in this sample. This average value might appear low; however, we argue that, using these index values in absolute terms to compare the "empowerment" or "disempowerment" status of communities or regions, as is done for instance in poverty analysis, should proceed with caution because the thresholds of empowerment at the indicator and question levels were chosen arbitrarily. Instead, the usefulness of our results arguably lie more in (1) comparing the empowerment values across populations and settings (Fig. 2) and (2) tracking change over time within populations. Our suggested approach departs from that of the WEAI, which uses a threshold within the five domains of empowerment (5DE) to assess the absolute value of an individual's empowerment. Moreover, we restricted our analysis to the individual level (1 woman in 1 household, individual level 5DE of the WEAI) and did not create a household aggregate gender parity index (as has been done with the WEAI) because we interviewed 
only women and limited the analysis to simple weighted averages to keep the analysis simpler and more intuitive for use in program monitoring. Baltenweck and Staal (2007) have discussed the value of maintaining simple rather than complex indicators in terms of their relating to real-world situations and providing information to target interventions.

Comparison of the WELI to the WEAI-inspired scores also is interesting with respect to indicator definitions. The distribution of score values generated by the lower adequacy levels inspired by WEAI is skewed considerably towards higher score values (Fig. 3). The resulting reduction in variation and the non-normal distribution make in-depth statistical analysis of scores more difficult. The difference in the results of the two methods implies that the arbitrary selection of adequacy levels has a large effect on estimates of the level of empowerment. By not deciding a priori on an adequacy level, WELI follows Alkire et al.'s (2013) approach of selecting a cut-off for empowerment by selecting a threshold that allows scope for improvement over time. For this reason, caution is needed when interpreting absolute index values. The reasoning behind the number of adequate questions for indicator achievement is discussed above. However, a related issue is the number of questions per indicator. It can be argued that with less than three questions per indicator results may appear erratic. The WELI has two indicators with fewer than three questions: Credit access (first question) and training access (second question). Further development of the WELI might include the identification of additional questions for these two indicators. Regarding indicator weights, the WELI followed the WEAI's approach of assigning equal weights, mainly because no data on domain or indicator priorities was accessible. Further exploration into the use of non-equal weights may strengthen the validity of the resulting index values but may result in a loss of simplicity that limits application for program monitoring. Conducting a thorough psychometric analysis of the WELI as a next step may inform revisions to scoring the WELI.

Reviewing the contributions of individual indicators to WELI scores, one might question the inclusion of "access to credit" among the WELI indicators. Because credit facilities were absent from the study communities, the scores related to it were zero for nearly all respondents. However, team deliberation and knowledge of the study area suggested that credit facilities were likely to emerge in this setting, so including such an indicator would permit an assessment of within-population change over time in this indicator, and its evolving contribution to women's overall empowerment. Including credit facilities as an indicator, also shows the importance of balancing context specificity with theoretically grounded, cross-context dimensions that may emerge in specific settings over time. A prior assessment of the current and/or future relevance of all selected indicators enhanced our confidence that the WELI and its components would continue to be meaningful over time.

\subsection{Women's Empowerment in Livestock Across Sites}

The WELI was created to capture changes in women's empowerment in the livestock sector because, as argued above, livestock farming presents unique opportunities and constraints that may affect women's empowerment differently than, for example, crop agriculture. The findings show substantial differences in empowerment across the studied sites, with women in high-intensity dairy sites (i.e. Lushoto) having higher empowerment in livestock than women in pastoralist systems with less dairy intensification (i.e. Handeni and Mvomero), while the women in sites having low levels of livestock assets and intensification (i.e. Kilosa) showed the lowest average level of empowerment. This finding might raise the question whether livestock farming is, in fact, an important determinant of women's empowerment (i.e. one could expect women's empowerment to be relatively high wherever livestock 
farming is practiced given the important role of livestock for women, as discussed at the beginning of this paper). Because dairy farming is indeed the most important source of livelihoods in all four study sites (International Livestock Research Institute 2013), the variation in empowerment values across the sites highlights how women's empowerment may be affected by the characteristics of different livestock farming systems. Whether a given dairy farming system has an effect on empowerment or vice versa (women's empowerment can affect the degree of dairy intensification) was not assessed in this study and is an interesting issue that needs further exploration. The findings showing a direct correlation between dairy intensification and women's empowerment also raise the question whether the WELI may not pick up other dimensions of women's empowerment in contexts where their livelihoods are derived from non-livestock related sources. However, because the WELI has been developed for systems in which livestock provides important livelihood contributions, this is not a question the WELI can address. Rather, the WELI investigates levels of and contributions to empowerment within livestock-dominated systems.

The findings show that the contribution of the dimensions and indicators to the overall value of individual empowerment differs considerably across the empowerment quartiles. In the lowest quartile (the least empowered respondents, average score: 0.13 ), the value of empowerment is mostly constituted by decisions about nutrition and extent and control over own time. In the highest quartile (most empowered respondents, average score: 0.70 ) all six dimensions contribute almost equally to the overall value of empowerment. These findings reveal how combining indicator-specific and composite analysis clarifies the differential contributions of each indicator to the overall score for empowerment at specific quartiles. Such information can help to target dairy interventions that aim to enhance women's empowerment by showing the dimensions that most need support and/or that can be leveraged to enhance other domains.

\subsection{The WELI and Definitions of Empowerment}

Process of empowerment Because WELI data for the current study was collected in a cross-sectional survey, it does not capture the processes of empowerment. Empowerment often is conceptualized as individual processes of change (Eyben and Napier-Moore 2009; Kabeer 2010). Prior research (Galiè et al. 2017b) has shown that empowerment pathways often are complex and non-linear. A decrease over time, for example, in the score for a component indicator of empowerment - such as access to training or information-might suggest increased self-awareness of limitations faced, a necessary step towards identifying solutions for self-determination. A single quantitative assessment of empowerment in a given context may preclude an accounting of the nature of changes in empowerment over time (Cheong et al. 2017). Repeated applications of the WELI within cohorts over time, with in-depth qualitative research would provide richer data to reveal and to interpret complex empowerment processes.

Gender relations and dynamics The process of empowerment starts with individuallevel ontological transformations in self-determination and self-recognition (Bartlett 2008). For these individual changes to be realized, others must recognize them through changes in power relations and in the distribution of resources and opportunities (Santarius and Sachs 2007). By applying the WELI only to women, the current study did not capture the nature of changing social and gender dynamics and the causes behind them. The authors, therefore, recommend applying the WELI with men and women involved in the livestock sector, and complementing this quantitative data collection with qualitative research to enhance an 
understanding of the unfolding of individual-level empowerment, changing gender dynamics, and the relational nature of empowerment.

Relevant dimensions and indicators The WELI, as developed here, includes standard dimensions and indicators of empowerment developed in consultation with experts from the focal area. Because understandings and dimensions of empowerment may be time, and context, specific (Kabeer 2012; Richardson 2017; Tsikata and Darkwah 2014), this tool may need some adaptation to be appropriate for other populations and settings to capture better local goals for self-determination. The WELI was developed by involving local expertise and based on a formative study. After its application, and to add depth to the findings, we conducted a qualitative and participatory study of what empowerment meant for the respondents and what dimensions were most relevant to them to measure changes in empowerment (Price et al. 2018). Such a study can be used to adjust the dimensions included in the WELI to new contexts and indicators, particularly if conducted at the initial stages of adapting the WELI to local contexts. Dimensions that coincide with universal ones can then be used for comparison across-settings while dimensions that are only locally relevant can be used for in-depth monitoring and assessment within the local population. Such an approach also may help expand the dimensions currently explored by the WELI to new ones such as collective empowerment (Yount 2017).

\subsection{Next Steps for Validation of the WELI}

The purpose of this paper has been to present the WELI and to compare WELI scores that were generated using the approach recommended by the creators of the WEAI. While this scoring approach has the benefit of simplicity, a next recommended step to validate the WELI is to perform a psychometric analysis of its component items (questions) and dimensions (or indicators). Since the WELI is new, one approach would be to explore the set of theoretically grounded dimensions first by performing an exploratory factor analysis. Taking into account the theory about the number of anticipated dimensions, expected item loadings, and model fit, a next step then would be to confirm the factor structure by estimating a confirmatory factor analysis, or CFA, in an independent sample. Finally, we would want to confirm that the measurement of the WELI was invariant across theoretically relevant subgroups, such as different educational, socioeconomic, or ethnic groups. These analyses might inform modifications to current approaches for generating WELI scores that take into account the differential weightings (or loadings) of items on factors (dimensions) of women's empowerment in the livestock sector. In general, as scales are developed to measure women's empowerment in different sectors, we recommend a thorough psychometric assessment of each scale to verify its ability to make comparisons in women's empowerment across groups and over time. We also recommend that a concise subset of items be identified that facilitate program monitoring (Yount 2017).

\section{Conclusions}

This paper presents the WELI, a tool developed to assess quantitatively the empowerment of women in the livestock sector. Use of the tool is appropriate in households where livestock is the main agricultural activity because its use increases accuracy and depth of findings. The WELI also is especially useful for measuring the impact of livestock projects 
on women's empowerment over time. The authors argue that integrating qualitative and participatory assessments of local perceptions of empowerment with indicators used in the WELI is a good way forward in providing data that can be compared across sites and that sheds light on empowerment as an individual and collective process. The approach also can be useful for integrating in the WELI other dimensions of empowerment that are locally relevant, therefore, expanding the scope of conceptualizations of empowerment currently included. We generally recommend applying the WELI in a longitudinal panel design to capture changes in empowerment, in parallel with qualitative in-depth analysis that can provide insights into the "hows" and "whys" of empowerment; both approaches will shed light on empowerment as a process of change. Finally, we also recommend applying the WELI and the recommended qualitative methods with women and men from the same community to account for the relational nature of empowerment. These insights can, in turn, help to contextualize the meaning of the WELI scores, allow for cross-sectional comparison of women's empowerment scores and processes, and inform strategies to enhance women's empowerment.

Acknowledgements The authors thank Amber Peterman, Peter Willadsen, and Sophie Theis for their constructive comments on an earlier version of this paper. We thank all donors that have globally supported our work through their contributions to the CGIAR system, in particular the United States Agency for International Development (USAID), Irish Aid and the CGIAR Research Program on Livestock and Fish. The usual disclaimers apply.

Open Access This article is distributed under the terms of the Creative Commons Attribution 4.0 International License (http://creativecommons.org/licenses/by/4.0/), which permits unrestricted use, distribution, and reproduction in any medium, provided you give appropriate credit to the original author(s) and the source, provide a link to the Creative Commons license, and indicate if changes were made.

\section{References}

Agarwal, B. (1997). Bargaining and gender relations: Within and beyond the household. Feminist Economics, 3(1), 37-41.

Alkire, S., \& Foster, J. (2011). Counting and multidimensional poverty measurement. Journal of Public Economics, 95(7-8), 476-487. https://doi.org/10.1016/j.jpubeco.2010.11.006.

Alkire, S., \& Santos, M. E. (2010). Acute multidimensional poverty : A new index for developing countries (OPHI worki). Oxford, UK: University of Oxford.

Alkire, S., Meinzen-Dick, R., Peterman, A., Quisumbing, A., Seymour, G., \& Vaz, A. (2013). Women's Empowerment in Agriculture Index. World Development, 52, 71-91.

Baltenweck, I., \& Staal, S. (2007). Beyond one-size-fits-all: Differentiating market access measures for commodity systems in the Kenyan highlands. Journal of Agricultural Economics, 58(3), 536-548. https:// doi.org/10.1111/j.1477-9552.2007.00129.x.

Bartlett, A. (2008). No more adoption rates! Looking for empowerment in agricultural development programmes. Development in Practice, 18(4-5), 524-538.

Bebbington, A. (1999). Capitals and capabilities: A framework for analyzing peasant viability, rural livelihoods and poverty. World Development, 27(12), 2021-2044.

Booysen, F. (2002). An overview and evaluation of composite indices of development. Social Indicators Research, 59, 115-151. https://doi.org/10.1023/A:1016275505152.

Cheong, Y. F., Yount, K. M., \& Crandall, A. A. (2017). Longitudinal measurement invariance of the Women's Agency Scale. Bulletin of Sociological Methodology/Bulletin de Méthodologie Sociologique, $134(1), 24-36$.

Chiwona-Karltun, L., Mkumbira, J., Saka, J., Bovin, M., Mahungu, N. M., \& Rosling, H. (1998). The importance of being bitter: A qualitative study on cassava cultivar preference in Malawi. Ecology of Food and Nutrition, 37(3), 219-245.

Cornwall, A. (2007). Pathways of women's empowerment. Open Democracy News Analysis, pp. 10-13. 
Covarrubias, K., Nsiima, L., \& Zezza, A. (2012). Livestock and livelihoods in rural Tanzania: A descriptive analysis of the 2009 national panel survey. Washington D.C.: World Bank. Retrieved May 29, 2018.

Cunningham, K., Ploubidis, G. B., Menon, P., Ruel, M., Kadiyala, S., Uauy, R., et al. (2015). Women's empowerment in agriculture and child nutritional status in rural Nepal. Public Health Nutrition, 18(17), 3134-3145. https://doi.org/10.1017/S1368980015000683.

Drydyk, J. (2013). Empowerment, agency, and power. Journal of Global Ethics, 9(3), 249-262. https://doi. org/10.1080/17449626.2013.818374.

Duflo, E. (2003). Grandmothers and granddaughters: Old-age pensions and intrahousehold allocation in South Africa. World Bank Economic Review, 17(1), 1-25.

Emory University, \& UN World Food Programme. (n.d.). Impact of a marketing intervention to empower women and to reduce the risk of intimate partner violence in Colombia: The SEED study baseline survey report. Atlanta, GA, USA.

Eyben, R., \& Napier-Moore, R. (2009). Choosing words with care? Shifting meanings of women's empowerment in international development. Third World Quarterly, 30(2), 285-300. https://doi. org/10.1080/01436590802681066.

FAO. (2011). The state of food and agriculture. Women in agriculture: Closing the gender gap for development. Rome, Italy: FAO. http://www.fao.org/docrep/013/i2050e/i2050e.pdf. Retrieved May 29, 2018.

FAO. (2012). Invisible guardians-women manage livestock diversity (No. 174). FAO animal production and health papers. Rome, IT.

Farnworth, C. R., \& Jiggins, J. L. S. (2003). Participatory plant breeding and gender analysis. Cali, Colombia: CGIAR Systemwide Program on Participatory Research and Gender Analysis (PRGA).

Ferreira, F. H. G., \& Lugo, M. A. (2013). Multidimensional poverty analysis: Looking for a middle ground. World Bank Research Observer, 28(2), 220-235. https://doi.org/10.1093/wbro/lks013.

Flintan, F. (2008). Women's empowerment in pastoral societies. New York: UNDP, Global Environment Facility.

Friis-Hansen, E., \& Duveskog, D. (2012). The empowerment route to well-being: An analysis of farmer field schools in East Africa. World Development, 40(2), 414-427. https://doi.org/10.1016/j.world dev.2011.05.005.

Galiè, A. (2013a). Empowering women farmers: The case of participatory plant breeding in ten Syrian households. Frontiers: A Journal of Women's Studies, 34(1), 58-92.

Galiè, A. (2013b). Governance of seed and food security through participatory plant breeding in ten Syrian households: Empirical evidence and gender analysis. In Natural Resources Forum (NRS), a United Nations Sustainable Development Journal, Vol. 37, pp. 31-42.

Galiè, A., Distefano, F., Kangogo, D., Mattioli, R., Wieland, B., \& Baltenweck, I. (2017a). Gendered perspectives on smallholder cattle production and health management in three sites in Tanzania. Journal of Gender, Agriculture and Food Security (Agri-gender), 2(3), 43-65.

Galiè, A., Jiggins, J., Struik, P. C. P. C., Grando, S., \& Ceccarelli, S. (2017b). Women's empowerment through seed improvement and seed governance: Evidence from participatory barley breeding in pre-war Syria. NJAS-Wageningen Journal of Life Sciences, 81, 1-8. https://doi.org/10.1016/j. njas.2017.01.002.

Galiè, A., Mulema, A., Mora Benard, M., Onzere, S. N., \& Colverson, K. E. (2015). Exploring gender perceptions of resource ownership and their implications for food security among rural livestock owners in Tanzania, Ethiopia, and Nicaragua. Agriculture \& Food Security, 4(1), 1-14. https://doi. org/10.1186/s40066-015-0021-9.

Goldman, M. J., \& Little, J. S. (2015). Innovative grassroots NGOS and the complex processes of women's empowerment: An empirical investigation from Northern Tanzania. World Development, 66, 762-777. https://doi.org/10.1016/j.worlddev.2014.09.005.

Grace, D., Roesel, K., \& Lore, T. (2014). Poverty and gender aspects of food safety and informal markets in sub-Saharan Africa. (ILRI Research Briefs No. 21), Nairobi, Kenya.

Halim, N., Yount, K. M., \& Cunningham, S. A. (2016). Do low-caste women legislators mean lower gender-caste gaps in primary schooling in India? Social Science Research, 58, 122-134. https://doi. org/10.1016/j.ssresearch.2016.01.002.

Halim, N., Yount, K. N., Cunningham, S., \& Pande, R. (2015). Women's political empowerment and inputs to primary schooling in India. Social Indicators Research, 125(3), 813-851. https://doi. org/10.1007/s11205-015-0870-4.

Heckert, J., \& Fabic, M. S. (2013). Improving data concerning women's empowerment in SubSaharan Africa. Studies in Family Planning, 44(3), 319-344. https://doi.org/10.111 1/j.1728-4465.2013.00360.x. 
Herrero, C., Martínez, R., \& Villar, A. (2012). A newer Human Development Index. Journal of Human Development and Capabilities, 13(2), 247-268. https://doi.org/10.1080/19452829.2011.645027.

Hill, C. (2011). Enabling rural women's economic empowerment: Institutions, opportunities and participation. UN Women Expert Group Meeting.

Ibrahim, S., \& Alkire, S. (2007). Agency and empowerment: A proposal for internationally comparable indicators. Oxford Development Studies, 35(4), 379-403. https://doi.org/10.1080/1360081070 1701897.

International Livestock Research Institute (ILRI). (2013). More milk by and for the poor: Adapting dairy market hubs for pro-poor smallholder value chains in Tanzania (MoreMilkIT). Nairobi, Kenya.

James, A. J., Verhagen, J., van Wijk, C., Nanavaty, R., Parikh, M., \& Bhatt, M. (2002). Transforming time into money using water: A participatory study of economics and gender in rural India. Natural Resources Forum, 26(3), 205-217. https://doi.org/10.1111/0165-0203.00022.

Jiggins, J. L. S. (2011). Foresight project. Science review SR: 48, Gender in the food system. London.

Kabeer, N. (1999). Resources, agency, achievements: Reflections on the measurement of women's empowerment. Development and Change, 30(May), 435-464.

Kabeer, N. (2010). Women's empowerment, development interventions and the management of information flows. IDS Bulletin, 41(6), 105-113.

Kabeer, N. (2011). Between affiliation and autonomy: Navigating pathways of women's empowerment and gender justice in rural Bangladesh. Development and Change, 42(2), 499-528. https://doi.org/10.111 1/j.1467-7660.2011.01703.x.

Kabeer, N. (2012). Empowerment, citizenship and gender justice: A contribution to locally grounded theories of change in women's lives. Ethics and Social Welfare, 6(3), 216-232. https://doi. org/10.1080/17496535.2012.704055.

Kilby, P. (2006). Accountability for empowerment: Dilemmas facing non-governmental organizations. World Development, 34(6), 951-963. https://doi.org/10.1016/j.worlddev.2005.11.009.

Kristjanson, P., Waters-bayer, A., Johnson, N., Tipilda, A., Njuki, J., Baltenweck, I., et al. (2010). Livestock and women's livelihoods: A review of the recent evidence (No. Discussion Paper 20). Nairobi, Kenya.

Kristjanson, P., Waters-Bayer, A., Johnson, N., Tipilda, A., Njuki, J., Baltenweck, I., et al. (2014). Livestock and women's livelihoods: A review of the recent evidence. In A. R. Quisumbing, R. Meinzen-Dick, T. L. Raney, A. Croppenstedt, J. A. Behrman, \& A. Peterman (Eds.), Gender in agriculture: Closing the knowledge gap (pp. 209-233). Dordrecht: Springer.

Malapit, H. J. L., \& Quisumbing, A. R. (2015). What dimensions of women's empowerment in agriculture matter for nutrition in Ghana? Food Policy, 52, 54-63. https://doi.org/10.1016/j.foodpol.2015.02.003.

Mason, R., Ndlovu, P., Parkins, J. R., \& Luckert, M. K. (2014). Determinants of food security in Tanzania: Gendered dimensions of household headship and control of resources. Agriculture and Human Values. https://doi.org/10.1007/s10460-014-9568-5.

Mayoux, L., \& Hartl, M. (2009). Guide for practitioners-Gender and rural microfinance: Reaching and empowering women. https://www.ifad.org/documents/10180/8551f293-2573-417d-908a-d1841359df 57. Retrieved May 29, 2018.

McGillivray, M. (1991). The Human Development Index : Yet another redundant composite development indicator? World Development, 19(10), 1461-1468. https://doi.org/10.1016/0305-750X(91)90088-Y.

Meinzen-Dick, R., Johnson, N., Quisumbing, A. R., Njuki, J., Behrman, J. A., Rubin, D., et al. (2014). The gender asset gap and its implications for agricultural and rural development. In A. R. Quisumbing, R. Meinzen-Dick, T. L. Raney, A. Croppenstedt, J. A. Behrman, \& A. Peterman (Eds.), Gender in agriculture: Closing the knowledge gap (pp. 91-115). Dordrecht: Springer.

Miedema, S., Haardörfer, R., Webb Girard, A., \& Yount, K. M. (n.d.). Women's empowerment in East Africa: Development of a cross-country comparable measure. World Development.

Miedema, S., Haardörfer, R., Webb Girard, A., \& Yount, K. M. (2017). Are measures of women's empowerment comparable across countries? A psychometric test of factor structure invariance across East Africa. In Poster session presented at the annual population association of american conference, 2729 April, Chicago, IL.

Ministry of Agriculture Livestock and Fisheries. (2016). The Tanzania smallholder livestock sector: A review based on the 2012/13 national panel survey. Dar Es Salam.

Mwaseba, D. J. B., \& Kaarhus, R. (2015). How do intra-household gender relations affect child nutrition? Findings from two rural districts in Tanzania. Forum for Development Studies, 42(2), 289-309. https:// doi.org/10.1080/08039410.2015.1020337.

Negin, J., Remans, R., Karuti, S., \& Fanzo, J. C. (2009). Integrating a broader notion of food security and gender empowerment into the African Green Revolution. Food Security, 1(3), 351-360. https://doi. org/10.1007/s12571-009-0025-z. 
Neumann, C. G., Murphy, S. P., Gewa, C., Grillenberger, M., \& Bwibo, N. O. (2007). Meat supplementation improves growth, cognitive, and behavioral outcomes in Kenyan children. The Journal of nutrition, 137(4), 1119-1123. http://www.ncbi.nlm.nih.gov/pubmed/17374691. Accessed May 9, 2017.

Njuki, J., \& Sanginga, P. C. (Eds.). (2013). Women, livestock ownership and markets. New York, USA: Earthscan USA/International Development Research Centre, Canada.

Ogato, G. S., Boon, E. K., \& Subramani, J. (2009). Improving access to productive resources and agricultural services through gender empowerment: A case study of three rural communities in Ambo District. Ethiopia. Journal of Human Ecology, 27(2), 85-100.

Price, M. J., Galiè, A., Marshall, J., \& Ngozichukwuka, A. (2018). Elucidating the linkages between women's empowerment in livestock and nutrition: A qualitative study of smallholder livestock raisers in Tanzania. Development in Practice, 28(4), 510-524. https://doi.org/10.1080/09614524.2018.1451491.

Quisumbing, A. R., Rubin, D., Manfre, C., Waithanji, E., van den Bold, M., Olney, D., et al. (2015). Gender, assets, and market-oriented agriculture: learning from high-value crop and livestock projects in Africa and Asia. Agriculture and Human Values. https://doi.org/10.1007/s10460-015-9587-X.

Ravallion, M. (2011). On multidimensional indices of poverty. Journal of Economic Inequality, 9(2), 235-248.

Ravallion, M. (2012). Mashup indices of development. World Bank Research Observer, 27(1), 1-32. https:// doi.org/10.1093/wbro/lkr009.

Reeves, H., \& Baden, S. (2000). Gender and development: Concepts and definitions (Bridge: development gender). Retrieved May 29, 2018 from http://www.bridge.ids.ac.uk/sites/bridge.ids.ac.uk/files/reports/ re55.pdf.

Richardson, R. A. (2017). Measuring women's empowerment: A critical review of current practices and recommendations for researchers. Social Indicators Research. https://doi.org/10.1007/s1120 5-017-1622-4.

Robeyns, I. (2003). Sen'S capability approach and gender inequality: Selecting relevant capabilities. Feminist Economics. https://doi.org/10.1080/1354570022000078024.

Roemer, J. E. (2008). Equality of opportunity. In S. N. Durlauf \& L. E. Blume (Eds.), The New Palgrave dictionary of economics (2nd ed., pp. 1-17). London: Palgrave, Macmillan.

Rubin, D., Seyoum, T., \& Caldwell, L. (2010). A calf, a house, a business of one's own: Microcredit, asset accumulation, and economic empowerment in GLCRSP projects in Ethiopia and Ghana. Global Livestock CRSp.

Sagar, A. D., \& Najam, A. (1998). The Human Development Index: A critical review. Ecological Economics, 25, 249-264.

Saith, A. (2006). From universal values to millennium development goals: Lost in translation. Development and Change, 37(6), 1167-1199.

Santarius, T., \& Sachs, W. (Eds.). (2007). Fair futures. London, UK: Zed Books.

Schmid, A. A. (1987). Property, power and public choice. New York: Praeger.

Sen, A. (1990). Development as capability expansion. In K. Griffin \& J. Knight (Eds.), Human development and the international development strategy for the 1990s (pp. 41-58). London, UK: MacMillan.

Sinharoy, S., Waid, J., Haardörfer, R., Wendt, A., Gabrysch, S., \& Yount, K. M. (2018). Women's dietary diversity in rural Bangladesh: Pathways through women's empowerment. Maternal and Child Nutrition. 14(1), e12489. https://doi.org/10.1111/mcn.12489.

The World Bank. (2009). Minding the stock: Bringing public policy to bear on livestock sector development. Retrieved May 29, 2018. Washington D.C. http://siteresources.worldbank.org/INTARD/Resources/ FinalMindingtheStock.pdf. Retrieved May 29, 2018.

Trommlerová, S. K., Klasen, S., \& Leßmann, O. (2015). Determinants of empowerment in a capabilitybased poverty approach: Evidence from The Gambia. World Development, 66, 1-15. https://doi. org/10.1016/j.worlddev.2014.07.008.

Tsikata, D., \& Darkwah, A. K. (2014). Researching empowerment: On methodological innovations, pitfalls and challenges. Women's Studies International Forum. https://doi.org/10.1016/j.wsif.2014.03.012.

UN Women, FAO, IFAD, \& WFP. (2012). Empowerment of women in rural areas is pre-requisite for global food security. Retrieved May 29, 2018 from http://www.fao.org/gender/news/detail/en/c/161413/.

Valdivia, C. (2001). Gender, livestock assets, resource management, and food security: Lessons from the SR-CRSP. Agriculture and Human Values, 18, 27-39.

Waithanji, E., Njuki, J., \& Bagalwa, N. (2013). Women's participation in livestock markets (research brief). Nairobi, Kenya. Retrieved May 29, 2018, from https:/www.idrc.ca/sites/default/files/sp/DocumentsE N/Participating-in-Markets-to-Improve-Womens-Welfare.pdf.

World Bank, FAO, \& IFAD. (2009). Gender in agriculture sourcebook. Washington DC: World Bank Publications. https://doi.org/10.1596/978-0-8213-7587-7. 
World Food Program. (2012). Comprehensive food security \& vulnerability analysis, Tanzania 2012. Retrieved May 29, 2018 from https://documents.wfp.org/stellent/groups/public/documents/ena/wfp25 9829.pdf?_ga=2.172052707.1555259642.1527599101-1634562328.1527599101.

Yount, K. M. (2017). A framework for measuring women's empowerment at multiple levels. https:// a4nh.cgiar.org/2017/05/01/a-framework-for-measuring-womens-empowerment-at-multiple-levels/. Accessed June 23, 2017.

Yount, K. M., VanderEnde, K. E., Dodell, S., \& Cheong, Y. F. (2015). Measurement of women's agency in Egypt: A national validation study. Social Indicators Research, 128(3), 1171-1192. https://doi. org/10.1007/s11205-015-1074-7. 